\title{
Análisis de Microhuellas de Uso Mediante Microscopio Electrónico de Barrido (MEB) de Artefactos Óseos de un Sitio Arcaico Tardio del Valle de Mauro (Región de Coquimbo, Chile): Aportes para una Reconstrucción Contextual
}

\author{
Use-Wear Analysis Through Scanning Electron Microscope
} (SEM) of Bone Tools from a Late Archaic Site in the Mauro Valley (Coquimbo Region, Chile): Contributions to a Contextual

Reconstruction.

Boris Santander ${ }^{\mathrm{y}}$ Patricio López M. ${ }^{I I}$

\section{RESUMEN}

Este trabajo presenta los resultados del análisis mediante Microscopio Electrónico de Barrido (MEB) realizado sobre siete artefactos óseos provenientes del sitio Arcaico Tardio (c.a. 4000-2000 a.p.) MAU085 (310 57'S - 710 01'O, Región de Coquimbo, Chile). Este análisis tuvo por objetivos identificar funcionalidades de un conjunto de artefactos óseos diversos y sus relaciones con la variedad de morfologías identificadas. Asimismo, se buscó relacionar los artefactos óseos con las evidencias artefactuales y ecofactuales, especificamente los restos liticos, ya que la hipótesis inicial de la funcionalidad de los artefactos óseos del sitio refiere su uso a herramientas para la talla y reavivado de bordes de puntas de proyectil y artefactos de corte. El análisis mediante Microscopio Electrónico de Barrido indica que los artefactos óseos fueron usados tanto en líticos así como en restos blandos como pieles y fibras textiles ampliando el uso de artefactos tradicionalmente asignados a retocadores.

Palabras clave: Microscopio Electrónico de Barrido, Artefactos óseos, Arcaico Tardio, Norte Semiárido, Chile.

\footnotetext{
Grupo Quaternário e Pré-História do Centro de Geociências (uID 73 - FCT Portugal), Portugal. Programa de Doctorado en Cuaternario y Prehistoria, Universitat Rovira i Virgili, España. Correo-e: boris.santander@ gmail.com.

ii Universidad Católica del Norte, Instituto de Investigaciones Arqueológicas y Museo Gustavo Le Paige (IIAM), Calle Gustavo Le Paige No 380, San Pedro de Atacama, Chile. Correo-e: patriciolopezmend@ yahoo.es

Recibido: enero 2011. Revisado: abril 2012 Aceptado: mayo 2012.
} 


\begin{abstract}
This paper presents the results of Scanning Electron Microscope (SEM) analysis performed on seven bone tools from MAU085, a Late Archaic site in the semiarid north of Chile (310 $57^{\prime} \mathrm{S}-71^{\circ} 01^{\prime} \mathrm{O}, \mathrm{IV}$ Region). The main objective of this analysis was to determine the function of a set of bone tools and their relation with the morphological variability identified. Given prior hypothesis linking the functionality of these bone tools to flaking and resharpening of projectile points and cutting artifacts, we sought complementary information in both artefactual and ecofactuals evidence, specifically the lithic remains. Analysis by Scanning Electron Microscope shows that the bone tools studied were used in lithic as well as soft contact materials such as leather/skin and textile fibers, thus expanding the use of artefacts traditionally considered bone retouchers.
\end{abstract}

Key-Words: Scanning Electron Microscope, Bone Tools, Late Archaic, Semiarid North, Chile.

\title{
INTRODUCCIÓN
}

Los análisis tipológicos han sido los más utilizados al momento de interpretar la funcionalidad de los artefactos óseos provenientes de sitios arqueológicos (Barandiarán 1967, González Morales 1986, Johnson 1989, Averbouh y Buisson 1996, Eiroa et al. 1999, Bertrand 1999, Julien et al. 2000). Si bien este tipo de análisis es necesario para clasificar conjuntos diversos en términos de la forma de los artefactos, y por ende sigue siendo utilizado en arqueología, el problema surge cuando la morfología no necesariamente define la funcionalidad debido a que tipologías similares pudieron ser utilizados sobre distintas texturas y con fines múltiples (Semenov 1964, Buc 2005, Santander 2011). Por esto, en las últimas décadas el análisis tipológico se ha complementado con técnicas más "finas" que han permitido profundizar e interpretar de mejor manera el uso de los artefactos. Dentro de estas técnicas, los microscópicos han sido de gran utilidad ya que permiten distinguir la diversidad de usos de artefactos morfológicamente similares (Semenov 1964, Newcomer 1974, Olsen 1979, Campana 1989, Peltier y Plisson 1989, Runnings et al. 1989, Shipman 1981, D`Errico y Villa 1997, Villa y D’Errico 2001, Buc 2005, 2008, 2011; Buc y Silvestre 2006, Santander 2010). Particularmente, el Microscopio Electrónico de Barrido (MEB en adelante) es una herramienta que ha sido profusamente utilizada en este tipo de artefactos tanto para caracterizar los microrrastros producto del uso de un artefacto, como para distinguir los vestigios naturales de los culturales. Este tipo de microscopios realiza un bombardeo de electrones sobre una pieza cubierta por algún material conductor (comúnmente oro, platino 
o carbono), la que es introducida en una cámara de vacío. Los electrones son captados por un sensor que transforma los datos a través de software y que reproduce gráficamente la información recopilada. Entre sus ventajas destaca su alta capacidad de magnificación (desde 1x hasta 300.000x), la óptima resolución que entrega, la posibilidad de realizar los análisis de las piezas con posterioridad a la captura de las imágenes, y la obtención de fotografías de manera inmediata con una profundidad de campo muchísimo mayor que aquella obtenida a través de medios ópticos. Además, el uso del microanálisis por difracción de Rayos X posibilita el análisis de composición química de partículas adheridas a la pieza en el instante de ser usada. Sin embargo, este método también presenta limitaciones. Las piezas deben ser metalizadas, lo que implica su preparación para ser sometidas a baños de minerales. En el caso de materiales como el hueso o artefactos líticos con alto componente de calcio, éste metalizado no puede ser removido con el uso de ácidos, por lo que es necesaria la fabricación de réplicas de alta resolución que permitan la observación microscópica.

En Chile, el estudio de la tecnología ósea, ha pasado prácticamente desapercibido dentro de las temáticas y problemas de la zooarqueología. Las investigaciones que prestan atención a este tipo de artefactos no alcanzan la decena (Becker 1994, García 2006, Jackson 1990, Lucero 2004, 2005; Lucero y Jackson 2005, Massone 1988, Santander 2009, 2010, 2011). Si este es el panorama para el estudio de la tecnología ósea, más complejos y escasos son los análisis microscópicos de conjuntos artefactuales, en donde a excepción de los trabajos de Lucero $(2004,2005)$ orientados a la malacofauna, y los análisis traceológicos de uno de los autores (Santander 2010, 2011), no existen referencias previas al uso de microscopía como parte del repertorio analítico en la zooarqueología nacional, siendo escasos además en toda Sudamérica (Scheinsohn 1997, Buc 2007, 2008, 2009, 2010, 2011; Buc y Loponte 2007, Buc y Silvestre 2006, Santander 2010, Stone 2011).

Dentro de este marco, el presente trabajo tiene por objetivo el identificar funcionalidades de un conjunto de artefactos óseos diversos procedentes del sitio MAU085 (Arcaico Tardío, IV Región de Chile) y sus relaciones con la variedad de morfologías identificadas; además de testear la hipótesis funcional de piezas que han sido previamente clasificadas por su forma, especialmente aquellas identificadas como "retocadores". Por otra parte, se buscó relacionar los artefactos óseos con las evidencias artefactuales y ecofactuales, particularmente los restos líticos, ya que la hipótesis inicial de la funcionalidad de los artefactos óseos del sitio refiere su uso a herramientas para la talla y reavivado de bordes de puntas de proyectil y artefactos de 
corte. Sin embargo, nuestra hipótesis de trabajo se basa en prescindir de preconceptos morfológicos para la determinación de las características funcionales del conjunto, considerando además, que la funcionalidad de los mismos puede sobrepasar la diversidad de formas presentes. En conjunto, estos objetivos se enmarcan en el interés de promover el uso de análisis de microhuellas como un complemento necesario al análisis tipológico, los cuales han sido escasamente abordados en Sudamérica.

\section{EL SITIO MAUO85}

Las ocupaciones Arcaico Tardías del Norte Semiarido (NSA en adelante), presentan mayores evidencias provenientes de la zona costera en contraste con la información disponible hacia el interior (Cornejo y Jackson 2004). En el caso de la costa, los sitios identificados para este periodo, se emplazan en zonas como puntillas costeras, terrazas marinas y áreas de desembocadura, bajo una lógica de asentamiento caracterizada por estrategias de apropiación de una amplia gama de recursos de disponibilidad inmediata (Méndez y Jackson 2004). La movilidad residencial se relaciona con emplazamientos elegidos en función de los recursos costeros recolectables (Méndez y Jackson 2004). En relación al conjunto lítico, como plantean Méndez y Jackson (2008), en base a la cronología del sitio San Pedro Viejo de Pichasca y a las secuencias culturales de las desembocaduras del NSA, se observa desde el Holoceno medio hasta la aparición de la cerámica durante el Holoceno tardío un conservadurismo en la manufactura de los tipos líticos más representativos, a saber, las puntas de proyectil triangulares. Este tipo de artefactos se asocian en el interior del NSA a campamentos a cielo abierto y en reparos rocosos, con evidencias que sugieren una movilidad residencial y con posibles traslados estacionales entre ambas vertientes andinas (Méndez y Jackson 2004).

Tal como han enfatizado Méndez y Troncoso (2004), uno de los problemas observados en la arqueología del NSA es la ausencia de un modelo interpretativo que aborde la transición entre los periodos Arcaico Temprano y el Período Alfarero Temprano (PAT en adelante), en donde los grupos de este último momento compartieron elementos culturales con los valles del Aconcagua, La Ligua-Petorca y la vertiente oriental de Los Andes (Méndez y Troncoso 2004). Los sitios correspondientes al PAT en el interior del valle del Choapa, han sido caracterizados en términos espaciales, por el “...emplazamiento de campamentos base en las quebradas tributarias principales y en las zonas altas de los valles, planicies de media altura, y de 
campamentos de tarea; y ocupaciones efímeras de terrazas bajas, y quebradas secundarias y/o estacionales" (Pavlovic 2004:40). Lo observado por Méndez y Jackson (2008) para Combarbalá (IV Región) para el PAT señala una fuerte dependencia de la caza y recolección, manteniendo una alta movilidad y una estrategia tecnológica conservadora, con evidencias líticas muy similares a las del Arcaico Tardío. Además, algunas evidencias de restos cerámicos Agrelo-Calingasta indican que durante el PAT se mantuvo una movilidad entre ambas vertientes de Los Andes (Méndez y Jackson 2008). Por su parte, datos recobrados en el río Pama (IV Región) de evidencias asignables al PAT indican actividades sostenidas de producción, uso y reemplazo de tecnología bifacial de caza y un descarte mínimo de tiestos cerámicos, lo que según Méndez et al. (2009) reflejan, en parte, un contexto de alta movilidad en la que la alfarería no estaría relacionada tanto con el procesamiento, consumo y almacenamiento de alimentos, sino que más bien en actividades de traslado de baja escala de algunos vegetales. Lo anterior, no constituye una ruptura con los patrones de actividad y uso del espacio de grupos cazadoresrecolectores (Méndez et al. 2009).

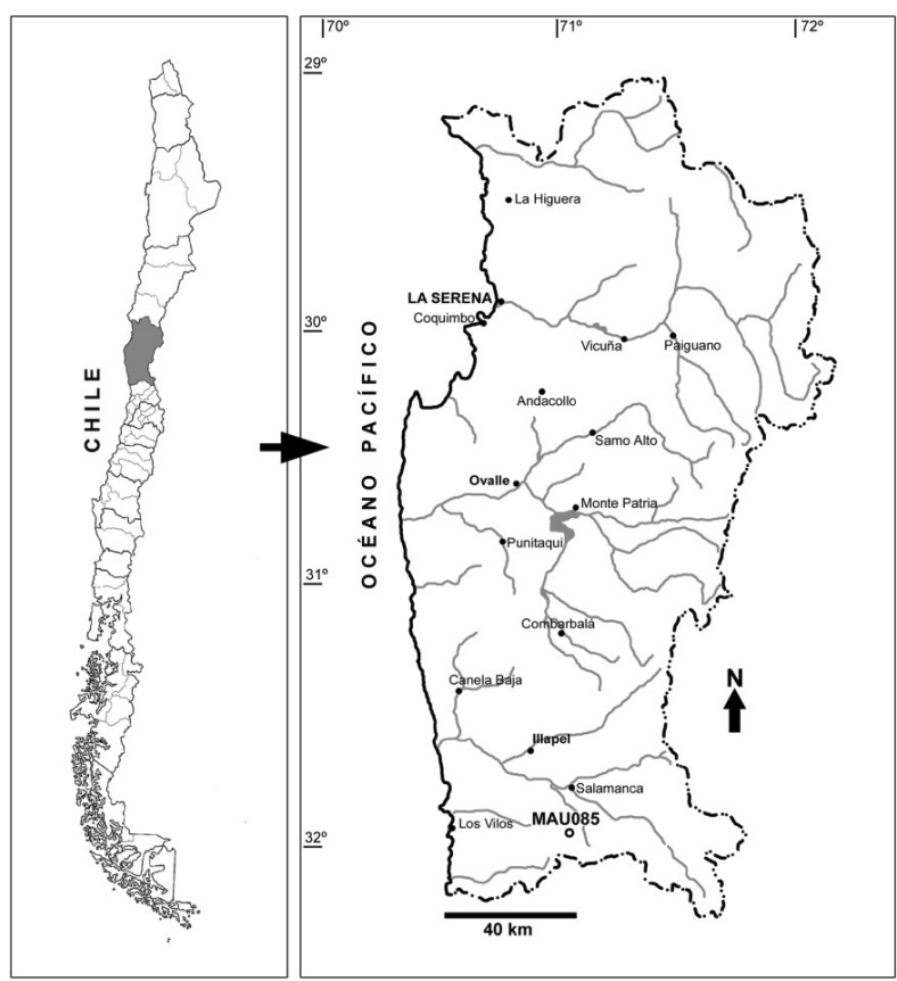

Figura 1: Ubicación del sitio MAU085.

Figure 1: Location of the MAU085 site. 
Ambos periodos, es decir, Arcaico Tardío y PAT se encuentran presentes en MAU085. Este sitio se ubica en el Valle de Mauro (31 $57^{\prime} \mathrm{S}-71^{\circ} 01^{\prime} \mathrm{O}$ ) sobre una pequeña loma emplazada al sur de la cuenca del estero El Pupío en la Comuna de Los Vilos, IV Región de Chile (ver Figura 1). Del sitio se excavaron un total de 45 unidades de $2 \mathrm{~m}^{2}$ en áreas de concentraciones de restos artefactuales y ecofactuales previamente identificados mediante una serie de sondeos. A partir de la excavación realizada en el sitio se lograron identificar tres áreas, a saber: 1) Área quincha, el cual corresponde a una zona caracterizada por una estructura horizontal y semi-ovalada elaborada en quincha (mezcla de barro que cubre un entramado de fibras vegetales entretejidas o bien dispuestas en una dirección determinada), asociada a escasos restos culturales y ecofactuales; 2) Área de descarte, cuyas evidencias corresponden a un abundante registro de restos de camélidos (afines a un morfotipo de gran tamaño), restos de microfauna y mesofauna (p.e. Abrocoma bennetti, Akodon sp., Lagidium viscacia, Callopistes maculatus, Callopistes palluma, Liolaemus sp., Lycalopex culpaeus, Lycalopex griseus, Octodon sp., Spalacopus cyanus, Canidae, entre otros), abundantes desechos de talla y retoque, artefactos de molienda, ganchos de estólica, cabezales líticos de proyectil (principalmente fragmentos de bases), restos de cerámica asignadas al PAT, fragmentos de vasijas elaboradas en quincha, dos láminas y una cuenta enrollada confeccionadas en cobre, entre otras evidencias (Cartajena et al. 2011, Jackson y Peralta 2011, Latorre et al. 2011). Tanto los fragmentos de cerámica y posiblemente los artefactos metálicos registrados sugieren una ocupación PAT de baja magnitud sobre la ocupación Arcaica tardía. Este registro se asociaba a fogones sellados con piedras y sectores de acumulaciones de desechos versus áreas más limpias. Por último, 3) Área de contextos funerarios, la que se emplaza en un sector más alejado de las zonas antes descritas, y se compone por el entierro de tres individuos (dos adultos y un neonato), cuyos contextos estaban asociados a pequeños fogones extendidos y en cubeta, sin ajuar u ofrendas.

La mayor concentración de restos se localiza en el estrato intermedio (Capa B), que corresponde a un sedimento orgánico y que promedia los 30 $\mathrm{cm}$ de espesor. A partir de 11 muestras de carbón, las ocupaciones fueron datadas por C14 entre los $3040 \pm 25$ y $2670 \pm 25$ años AP (ver Tabla 1). El conjunto de evidencias del sitio MAU085 sugieren que éste funcionó como un campamento enfocado al procesamiento y consumo mayoritariamente de camélidos y en menor medida de faunas de menor talla, además de actividades de reemplazo de puntas de proyectil de astiles, talla y retoque de artefactos de procesamiento y apropiación. La ubicación del sitio, sobre una pequeña loma que domina la parte baja del valle, fue ideal para el desarrollo de 
actividades cinegéticas, mientras que la cercanía del sitio con el Estero Pupío representó una ventaja significativa para la obtención de agua y recolección de recursos vegetales. Especialmente interesante es el Sector Quincha el que se caracteriza por una baja densidad de restos artefactuales y ecofactuales, salvo el registro de manos de moler distribuidas en su perímetro.

\begin{tabular}{|c|c|c|c|c|c|c|c|}
\hline UNIDAD & SECTOR & NIVEL & CAPA & RASGO & MATERIAL & ID Lab. & $\begin{array}{c}\text { C14 ańos } \\
\text { BP }\end{array}$ \\
\hline K8 & - & $(20-30 \mathrm{~cm})$ & B1 & - & Carbón & 9926 & $2840 \pm 25$ \\
\hline G6 & Quincha & $2(10-20 \mathrm{~cm})$ & B & - & Carbón & 9927 & $2670 \pm 25$ \\
\hline L4 & - & $(30-40 \mathrm{~cm})$ & B & - & Carbón & 9928 & $2770 \pm 25$ \\
\hline G7 & Quincha & - & B & - & Carbón & 9929 & $2830 \pm 25$ \\
\hline F15 & - & $5(40-50 \mathrm{~cm})$ & - & - & Carbón & 9930 & $2800 \pm 25$ \\
\hline C17 & - & $7(60-70 \mathrm{~cm})$ & - & Fogón & Carbón & 9931 & $2910 \pm 25$ \\
\hline D17 & - & $4(40-50 \mathrm{~cm})$ & B & Rasgo 1 & Carbón & 9932 & $2870 \pm 25$ \\
\hline C17-C18 & Individuo & $(85-95 \mathrm{~cm})$ & - & Rasgo 2 & Carbón & 9933 & $2870 \pm 25$ \\
\hline A13 & - & $4(30-40 \mathrm{~cm})$ & B & - & Carbón & 9934 & $2890 \pm 25$ \\
\hline F5 & Quincha & - & Quincha & - & Carbón & 9935 & $2860 \pm 25$ \\
\hline F6/cuad SE & - & $35 \mathrm{~cm}$ & - & Bajo quincha & Carbón & 9937 & $3040 \pm 25$ \\
\hline
\end{tabular}

Tabla 1: Fechados por C14 de muestras de carbón del sitio MAU085. Muestras procesadas en el "Center for Applied Isotope Studies (CAIS), Georgia University".

Table 1: 14C dates from the MAU085 site. Charcoal samples processed at the Center for Applied Isotope Studies (CAIS), Georgia University.

En el sitio MAU085 se identificaron tres capas estratigráficas. Desde arriba hacia abajo, la primera corresponde a la Capa A, en la cual se identificaron escasos restos arqueológicos, entre ellos fragmentos de cerámica asignada al Periodo Alfarero Temprano (PAT), la Capa B en donde se concentra la mayor parte de la ocupación Arcaica tardía, y por último la Capa $\mathrm{C}$ que corresponde a un estrato prácticamente estéril y en el cual se observaron materiales que casi en su totalidad provienen de la intersección con la Capa B. En total se contabilizaron 179 artefactos óseos, de los cuales $45(25,1 \%)$ provienen de la Capa A, $121(67,6 \%)$ de la Capa B, $3(1,7 \%)$ de la Capa C, $8(4,5 \%)$ sin registro estratigráfico y 2 artefactos $(1,1 \%)$ de la superficie. Los artefactos de la Capa A provienen del límite entre esta capa y la $\mathrm{B}$, por lo que es probable que la mayor parte esté asociado a la ocupación Arcaica tardía. Las unidades con mayor cantidad de artefactos corresponden 
a G18 y H17 (área de descarte), ambas con 14 objetos, la mayor parte de los cuales fueron recobrados de la Capa B.

De acuerdo a criterios morfológicos se identificaron cinco categorías generales que agrupan a todos los extremos activos, las cuales corresponden a extremos (1) aguzados romos, (2) aguzados, (3) rectangulares, (4) redondeados, y (5) biselados. De la muestra total, los extremos aguzados romos corresponden a 58 especímenes $(32,4 \%)$, los aguzados a $39(21,8 \%)$, los rectangulares a $2(1,1 \%)$, y los extremos redondeados a $22(12,3 \%) ; 2$ artefactos $(1,1 \%)$ presentaban extremos elaborados en ambos extremos (biapuntados, los cuales no se abordan en el presente estudio), 4 piezas $(2,4 \%)$ corresponden a fragmentos óseos perforados, en tanto que 51 piezas $(28,5 \%)$ no exhiben un extremo distal que pueda ser identificado, aun cuando presentan otras características que permitan definirlos como artefactos (pulidos intencionales o huellas de uso macroscópicas, por ejemplo). Por último, tan sólo 1 borde biselado $(0,6 \%)$ fue registrado.

En relación a los huesos utilizados como soportes para la confección de los artefactos, la gran mayoría se compone por huesos largos indeterminados con 135 especímenes (75,4\%), 16 huesos planos (8,9\%), 14 indeterminados (7,8\%), 9 metapodios indeterminados (5,0\%), 1 fragmento de diente con su raíz pulida (0,6\%), 1 húmero $(0,6 \%), 1$ costilla $(0,6 \%), 1$ incisivo $(0,6 \%)$ y 1 carpo de camélido $(0,6 \%)$. Esta composición de los materiales se condice con la morfología de los artefactos, atendiendo a una estrecha relación morfogeométrica de las piezas, como ha sido señalado por Scheinsohn (1993-1994, 1997).

\section{MATERIAL y MÉTODOS}

En total se analizaron en el MEB 7 instrumentos óseos, seleccionados entre los artefactos que representan la diversidad morfológica de extremos aguzados romos, redondeados y aguzados identificada en el sitio MAU085 (ver Figura 2), y que mantienen un estado de conservación macroscópico favorable; los cuales se detallan en la Tabla 2. Para el análisis por MEB, las piezas fueron sometidas a un baño de agua potable rápido, inferior a los 3 minutos, y posteriormente introducidas en un tanque de ultrasonido con agua durante dos ciclos de 10 minutos, para remover restos más finos de sedimento adherido. 

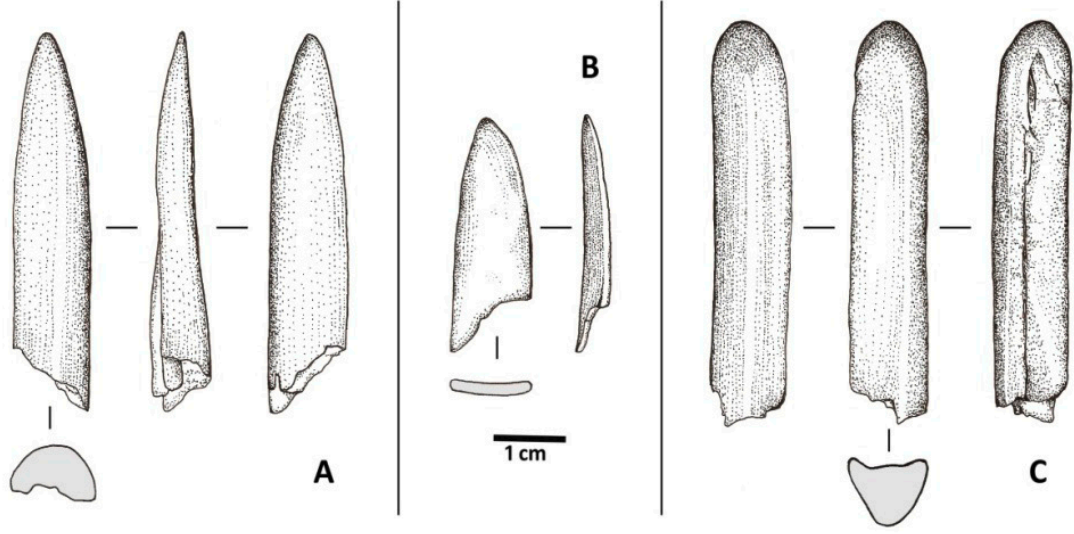

Figura 2: Dibujo de las categorías morfológicas observas en el sitio MAU085: A. Aguzado (Artefacto 1), B. Aguzado Romo (Artefacto 3) y C. Redondeado (Artefacto 7).

Figure 2: Drawing of the observed mophological categories in the MAU085 site: A. Sharpened, B. Sharpened Dull, and C. Rounded

\begin{tabular}{|c|c|c|c|}
\hline Código de Artefacto & Área de Procedencia & Número asignado & Descripción Morfológica \\
\hline MAU085/D4/A/Nivel 3 & Sector Quincha & 1 & Aguzado \\
\hline MAU085/F16/B/Nivel 5 & Área de Descarte & 2 & Aguzado \\
\hline MAU085/D17/B/Nivel 3 & Área de Descarte & 3 & Aguzado romo \\
\hline MAU085/H17/B/Nivel 10-20 & Área de Descarte & 4 & Aguzado romo \\
\hline MAU085/E17/B/Nivel 4 & Área de Descarte & 5 & Aguzado romo \\
\hline MAU085/G19/B/Nivel 2 & Área de Descarte & 6 & Redondeado \\
\hline MAU085/F16/B/Nivel 3 & Área de Descarte & 7 & Redondeado \\
\hline
\end{tabular}

Tabla 2: Artefactos óseos del sitio MAU085 seleccionados para el análisis por MEB.

Table 2: Bone tools from the MAU085 site selected for analysis by SEM.

Debido a las características señaladas del MEB, y para asegurar la integridad de los artefactos analizados, las muestras fueron replicadas a partir de moldes de silicona dental $\mathrm{C}$ de alta impregnación y baja deformidad. A partir de estos moldes se extrajeron positivos realizados en resina epóxica, las cuales fueron bañadas por una película de oro-paladio. Para el análisis microscópico fue utilizado un MEB Jeol 5410@ acoplado al software Anamaker $@$ con el fin de generar las imágenes espectrópicas. Este trabajo fue llevado a cabo en el Laboratorio de Microscopía Electrónica del Departamento de Ingeniería Metalúrgica de la Universidad de Santiago de Chile (USACH). Posteriormente, las imágenes resultantes fueron 
comparadas con muestras propias (Santander 2010), una réplica usada para la talla lítica y (ver Figura 3) patrones disponibles en la literatura dedicada al análisis de huellas de uso (Buc 2007, 2008, 2011; Stone 2010).

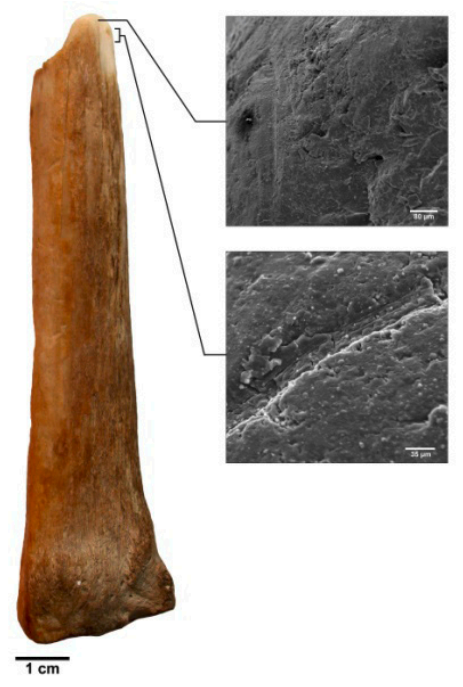

Figura 3: Retocador experimental con detalles obtenidos por MEB. Nótese las características de las estrías en el ápice de la pieza.

Figure 3: Experimental retoucher with details obteined through SEM. Note the characteristics use-wear traces at the tip of the tool.

\section{ANÁLISIS MICROSCÓPICO}

\section{Artefacto 1: Extremo aguzado}

Corresponde a un fragmento carbonizado de diáfisis de hueso largo de mamífero con su extremo distal aguzado y una sección transversal ovalada (Figura 4). Presenta una superficie bastante irregular, lo que unido a algunos defectos en la preparación de la réplica (ligados a la preservación original del fragmento) dificulta su observación en algunos puntos de la microtopografía ósea. Pese a lo anterior, se pueden apreciar claramente estrías gruesas, de fondo pulido y orientadas perpendiculares al eje de la pieza y con un borde igualmente pulido. Este tipo de estrías han sido reportadas en estudios previos (Santander 2010, Stone 2011, Buc 2011), como resultado de acciones relacionadas con la perforación de pieles a través de rotación perpendicular. 

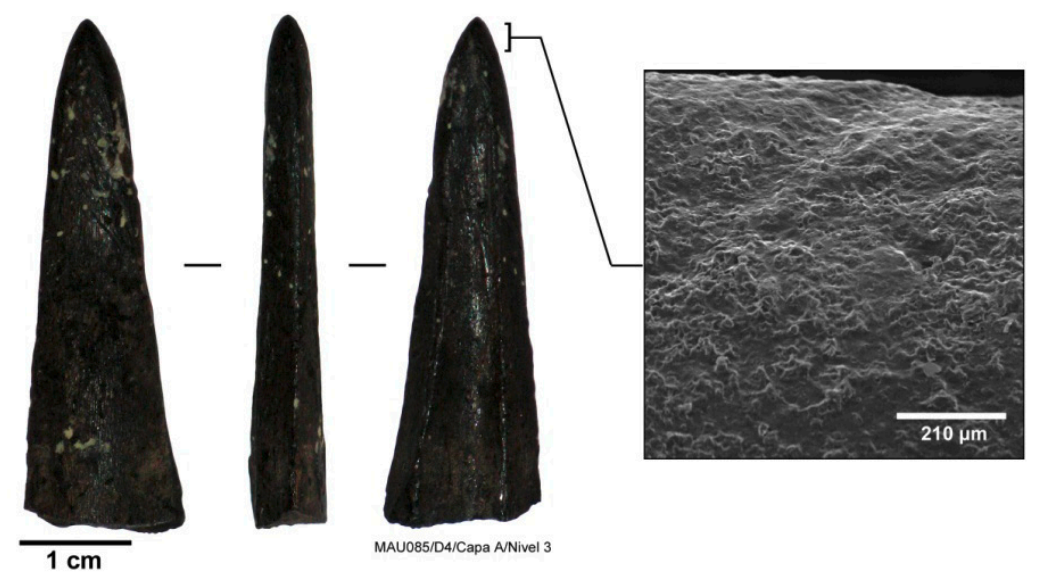

Figura 4: Detalles de microhuellas observadas en el Artefacto 1 (extremo aguzado).

Figure 4: Details of microtraces observed on Artifact 1 (Sharpened end).

\section{Artefacto 2: Extremo aguzado}

Corresponde a la porción distal de un artefacto de extremo aguzado y sección transversal ovalada. Se encuentra extensamente pulido a nivel macro y microscópico, aun cuando la acción de raíces ha generado radículas importantes en la superficie del mismo. A pesar de esto, las estrías presentes en la superficie del hueso son perfectamente distinguibles tanto en su ubicación como en sus atributos (ver Figura 5). Esta pieza, posee estrías longitudinales finas y paralelas, con cúspides pulidas y superficies ligeramente redondeadas, semejantes a las definidas por Santander (2010), para artefactos experimentales utilizados en la perforación por punción de piel fresca.

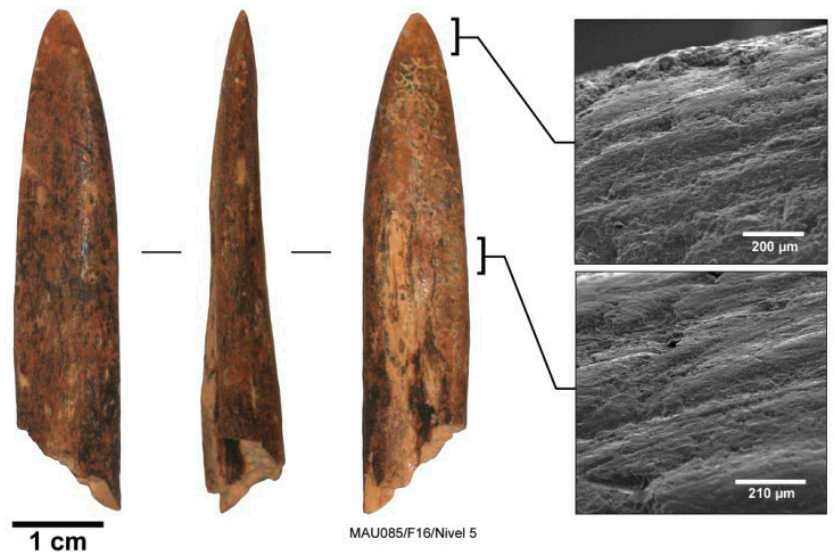

Figura 5: Detalles de microhuellas observadas en el Artefacto 2 (extremo aguzado).

Figure 5: Details of microtraces observed on Artifact 2 (Sharpened end). 


\section{Artefacto 3: Extremo aguzado romo}

Corresponde a un artefacto de extremo distal aguzado romo y de sección transversal plana, construido sobre un fragmento medial de costilla de mamífero. La pieza presenta un notorio pulimento en ambas caras y bordes. Este tipo de pulimento es notorio, aun a simple vista. A través de la observación mediante MEB, el Artefacto 3 presenta escasas huellas, las cuales en su mayoría tienen que ver con superficies muy pulidas, homogéneas y redondeadas, marcadas por huellas postdeposicionales invasivas.

Dispersas por la superficie ósea, se encuentran estrías finas, multidireccionales, y desorganizadas, las que están bastante pulidas en la cúspide de las estrías y que parecen corresponder a estriaciones de manufactura que son progresivamente obliteradas por la acción sobre materiales blandos (Figura 6). En concreto, este mismo patrón de obliteración de estrías de manufactura con pulimentos bastante homogéneos, ha sido reportada en artefactos para la producción de piezas textiles (Santander 2010).

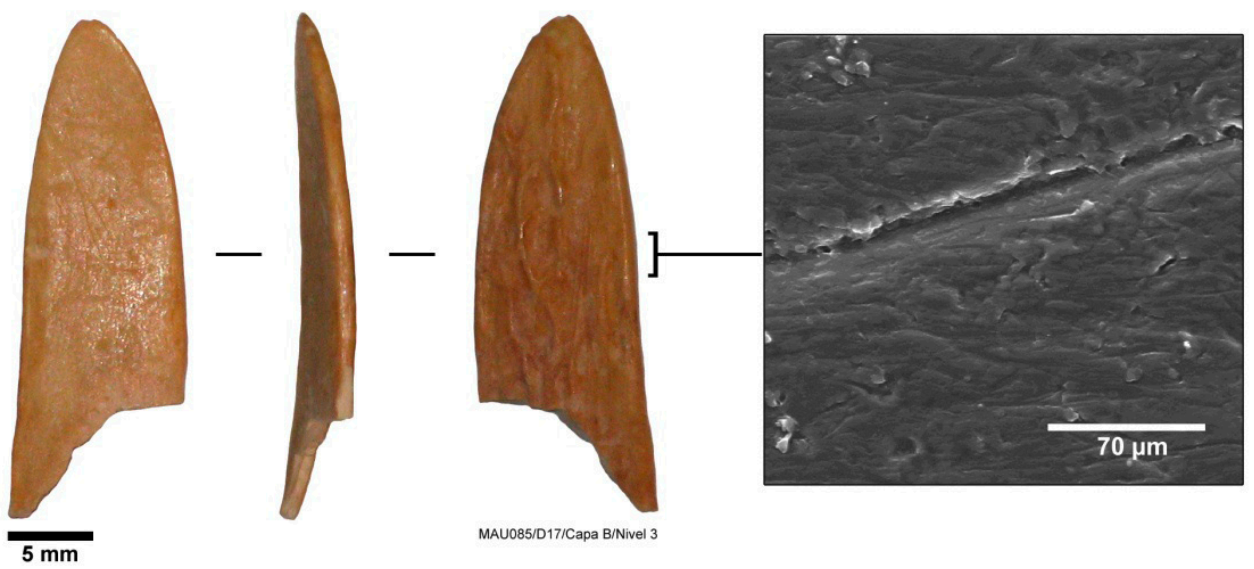

Figura 6: Detalle de microhuella observada en el Artefacto 3 (aguzado romo). Figure 6: Details of microtraces observed on Artifact 3 (Sharpened Dull end).

\section{Artefacto 4: Extremo aguzado romo}

Corresponde a un fragmento de diáfisis de metapodio de camélido. De extremo aguzado romo y sección sub-triangular/ovalada, la pieza únicamente conserva la porción distal, en donde se ubica el extremo activo de la misma. La diferente coloración de los frentes de fractura revela una rotura postdeposicional, que puede estar además unida a un leve grado de 
meteorización exhibido. Con todo, la pieza posee estrías de diferente grosor, algunas, producto de la manufactura, que son suavizadas por el pulido del uso, y otras realizadas sobre el pulido, abruptas y sin pulimento interno o en las cúspides (Figura 7). Nuevamente, la morfología y ubicación de las huellas, permite suponer la utilización de la pieza como retocador extremodistal.
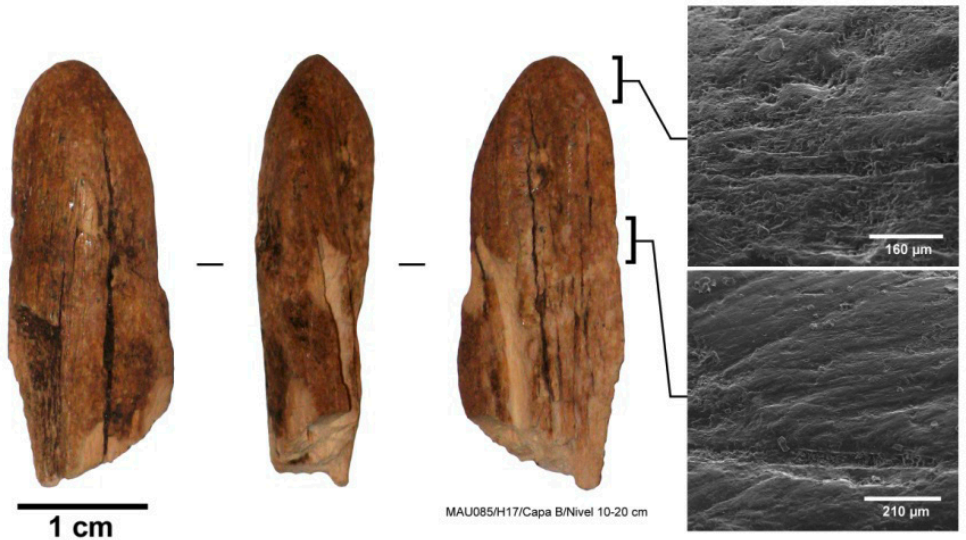

Figura 7: Detalles de microhuellas observadas en el Artefacto 4 (extremo aguzado romo).

Figure 7: Details of microtraces observed on Artifact 4 (Sharpened Dull end).

\section{Artefacto 5: Extremo aguzado romo}

El Artefacto 5 fue elaborado en un fragmento de hueso largo de mamífero de extremo distal aguzado romo y sección transversal triangular. A nivel macroscópico, presenta desconchamientos intensivos en la zona que rodea al ápice y un posible lascamiento en el extremo distal. El análisis de las imágenes obtenidas a través del $\mathrm{MEB}$, revela estrías oblicuas, gruesas, abruptas y paralelas, de borde y fondo irregular (ver Figura 8). Las huellas aparecen mayoritariamente paralelas, sin embargo, algunas estrías de menor tamaño parecen estar obliteradas por algunos posibles defectos en la réplica (burbujas). Las estrías evidenciadas coinciden con actividades de contacto intensivo con material duro y anguloso, por lo que se supone que la pieza fue utilizada como compresor extremo-distal para el retoque por presión de materias primas líticas. 


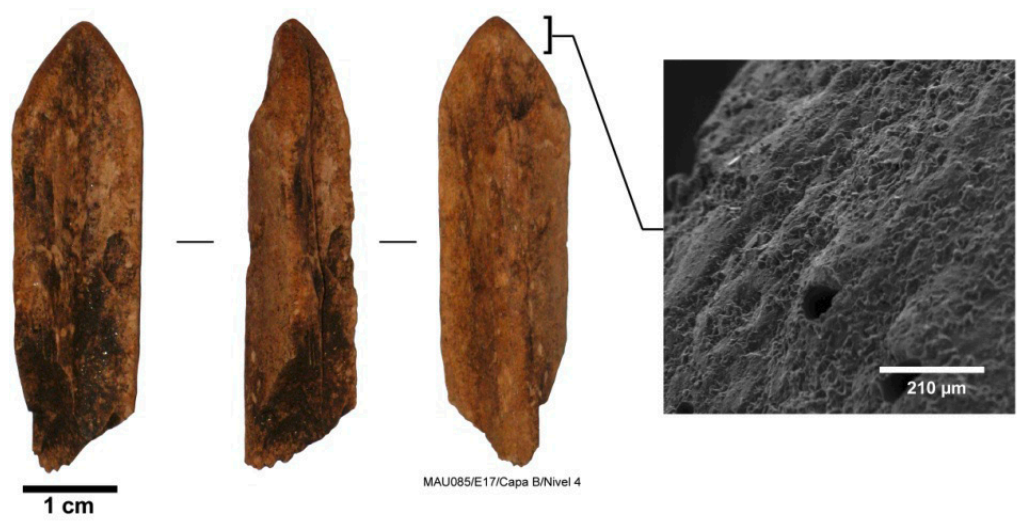

Figura 8: Detalles de microhuellas observadas en el Artefacto 5 (extremo aguzado romo).

Figure 8: Details of microtraces observed on Artifact 5 (Sharpened Dull end).

\section{Artefacto 6: Extremo redondeado}

Corresponde a un artefacto de extremo redondeado (con un ápice relativamente proyectado hacia distal) y sección transversal triangular, construida sobre el borde de un metapodio de camélido. La pieza, si bien se encuentra afectada por procesos post-deposicionales (especialmente por exposición a la intemperie), conserva huellas de manufactura y uso bastante notorios, aun a simple vista. El examen mediante $\mathrm{MEB}$, reveló estrías de grosor variable en el ápice, de perfiles angulosos y sin una orientación direccional preferente. Estas estrías se encuentran rodeadas por una superficie pulida, pero sus cúspides presentan ligeras irregularidades que parecen indicar que fueron generadas con posterioridad al pulimento de la superficie (Figura 9). Todos estos indicadores, definen a la pieza como un compresor para talla lítica por retoque, también llamados retocadores extremo-distales. 


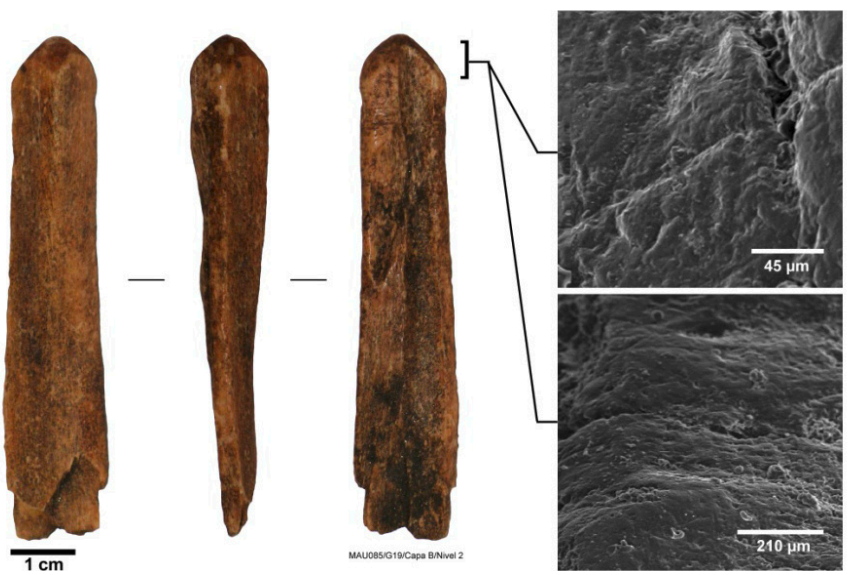

Figura 9: Detalles de microhuellas observadas en el Artefacto 6 (extremo redondeado).

Figure 9: Details of microtraces observed on Artifact 6 (Rounded end).

\section{Artefacto 7: Extremo redondeado}

Corresponde a un fragmento de diáfisis de metapodio proveniente de un camélido de talla grande. De extremo redondeado y sección ovalada, la pieza conserva la porción distal y parte del fuste. La observación al $\mathrm{MEB}$, no permite identificar huellas claras en relación a alguna actividad en específico, probablemente debido a problemas en la réplica del artefacto (Figura 10). Pese a esto, morfológica y macroscópicamente, la pieza pareciera corresponder a un compresor extremo-distal para el retoque por presión de materias primas líticas.

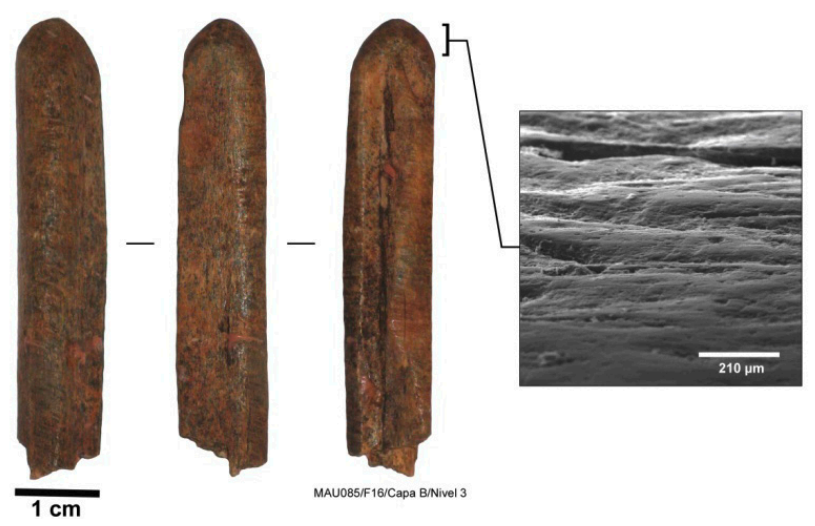

Figura 10: Detalles de microhuellas observadas en el Artefacto 7 (extremo redondeado).

Figure 10: Details of microtraces observed on Artifact 7 (Rounded end). 


\section{DisCUSIÓN Y CONCLUSIONES}

Los materiales analizados permitieron identificar una serie de actividades en las cuales los artefactos óseos parecen resultar de particular importancia. En primer lugar, resulta claro que las actividades de talla por retoque marginal evidenciadas en el sitio, contaron con la participación de compresores extremo-distales de hueso, los cuales presentan una morfología bastante estandarizada, con extremos aguzado-romos y redondeados y sección transversal triangular o subtriangular. Las estrías de uso evidenciadas en las muestras analizadas correspondientes a este tipo de artefactos depositadas en contextos de basural- permiten definir un comportamiento bastante claro relativo a la producción de artefactos líticos en un escenario mayor de actividades, en los cuales las piezas descartadas son acumuladas y transportadas hacia sectores diferenciados.

Por otra parte, piezas de morfología plana y extremo aguzado, parecen estar relacionadas con procesos de producción textil, o al menos, su utilización como parte de un proceso complejo de aprovechamiento de fibras de origen animal. La morfología de la superficie del artefacto analizado (Artefacto 3) no presenta rastros de abrasión con partículas duras, sino se evidencia un claro patrón de pulido suave pero intenso que obtura las estrías producto del proceso de producción del artefacto. Este tipo de huellas, ya ha sido observado microscópicamente en contextos arqueológicos como experimentales, fortaleciendo la hipótesis del uso de este tipo de piezas (aunque con morfologías diferentes) en el trabajo textil (Santander 2010, Stone 2011). En el sitio MAU085 no se registraron evidencias de textiles elaboradas en fibras animales aunque se observaron improntas de cestería. Para el PAT, las evidencias de textiles, si bien escasas por problemas de conservación en el norte semiárido chileno, son efectivas al igual que el trabajo de esteras con fibras vegetales (Niemeyer et al. 1997). No obstante, los artefactos de morfologías planas y extremos aguzados provienen de la ocupación Arcaica Tardía, siendo la ocupación PAT más bien marginal. Por otra parte, si se consideran además evidencias de áreas con mejor preservación, el uso de fibras de camélidos prioriza las de camélidos silvestres tanto de vicuñas por su calidad, como las de Guanaco (Lama guanicoe) por su resistencia (Cartajena et al. 2009). Por esto, la abundancia de restos de camélidos en MAU085 pudo relacionarse a actividades iniciales de obtención de fibras en comunión a las actividades de procesamiento para el consumo.

Otro aspecto interesante guarda relación con artefactos de extremo aguzado, que presentan huellas claras de utilización sobre materias primas 
blandas de origen animal, como cuero o piel en estado fresco. Este tipo de actividades resultan esperables en un contexto en el cual el aprovechamiento de los recursos animales sobrepasa el mero consumo de proteínas de origen animal, sino que referencian actividades de obtención de subproductos como la piel y el cuero.

En base a las evidencias presentadas, es posible suponer una utilización del sitio compatible con actividades domésticas que sobrepasan el uso del mismo como campamento específico de tareas, siendo un espacio en el cual se desarrollaron actividades que requieren de una mínima estabilidad espacial, como el aprovechamiento de recursos animales secundarios como la piel y/o fibras. En ese sentido, la incorporación de tecnologías textiles y/o de peletería, permitiría ampliar la perspectiva con respecto al nivel de movilidad de los habitantes del Valle de Mauro hacia fines del Arcaico Tardío, en un escenario en el que nuevas tecnologías se van sumando a las ya conocidas para el periodo. La gran cantidad de restos faunísticos recuperados dentro del sitio, dan pie para suponer no sólo una intensa actividad de consumo, sino además las posibilidades de aprovechamiento de los subproductos animales que se generan como consecuencia de las actividades de caza.

Si bien el Artefacto $\mathrm{N}^{\circ} 1$, recuperado del Área Quincha, presenta huellas interpretadas como resultado de la perforación de cueros, debido a lo escaso de la muestra, no es posible inferir una distribución espacial de tareas específicas dentro del sitio, presentándose como una temática necesaria de evaluar en futuros trabajos.

Por último, cabe destacar la relevancia de este tipo de análisis y de clasificaciones morfológicas estandarizadas en el estudio de artefactos óseos. Este último punto es de gran relevancia, puesto que clasificaciones a partir de criterios morfológicos evitan los sesgos de denominaciones que de por sí implican funcionalidad (i. e. punzones, retocadores, etc.). En este sentido, consideramos que los análisis morfológicos y traceológicos deben llevarse a cabo conjuntamente, con el fin de generar marcos de referencia elaborados con bases más sólidas.

Agradecimientos: El presente trabajo fue financiado por Minera Los Pelambres, "Proyecto Arqueológico Mauro", en el marco del Sistema de Evaluación de Impacto Ambiental y dirigido por el Departamento de Antropología de la Universidad de Chile. Nuestros agradecimientos a la colega Isabel Cartajena por sus comentarios a una versión inicial de este trabajo; a las colegas Camila Opazo, Bárbara Rivera, María Paz Casorzo, y al investigador Douglas Jackson por su ayuda en el análisis zooarqueológico del 
sitio MAU085. Nuestra gratitud también a Gladys Olivares del Laboratorio de Microscopia Electrónica del Departamento de Ingeniería Metalúrgica de la Universidad de Santiago de Chile (USACH), por su ayuda en la obtención de las imágenes. Por último deseamos agradecer a Donald Jackson por facilitar el retocador experimental utilizado como referencia en el presente trabajo; a Daniel Pascual y Daniel Pavlovic por las facilidades otorgadas en esta investigación y a los dos evaluadores anónimos cuyas sugerencias permitieron mejorar el presente trabajo.

\section{Bibliografía}

Averbouh, A. y D. Buisson. 1996. "Approche morpho-fonctionnelle des objets nommés "lissoirs": proposition d'une fiche analytique théorique". Antiquités nationales 28: 41-46.

Barandiarán Maestu, I. 1967. El Paleomesolitico del Pirineo Occidental. Bases para una sistematizacion tipológica del instrumental óseo paleolitico. Universidad de Zaragoza, Zaragoza, Espańa.

Becker, C. 1994. "Desde el Período Alfarero Temprano al Medio/Tardío a través de la lectura de sus restos faunísticos". Boletín del Museo Regional de la Araucanía 5: 41-52.

Bertrand, A. 1999. Les armatures de sagaies magdaléniennes en matiére dure animale dans les Pyrénées. International Series, 773. Oxford.

Buc, N. 2005. "Análisis microscópico de instrumentos óseos del humedal del Paraná Inferior. Una primera aproximación experimental. "En Entre pasados y presentes. Trabajos de las VI Jornadas de Jóvenes Investigadores en Ciencias Antropológicas, editado por A. Cetti, A. Re, D. Rindel y P. Valeri, pp: 262279. INAPL, Buenos Aires. Publicación en CDROM.

----- 2007. "Ser o no ser: arpones y “arpones B" en el humedal del Paraná inferior". En Arqueología en las Pampas, editado por C. Bayón, A. Pupio, M. I. González, N. Flegenheimer y M. Frère, tomo I: 325-342. Sociedad Argentina de Antropología, Buenos Aires.

----- 2008. Análisis de Microdesgaste en Tecnología Ósea. El caso de Punzones y Alisadores en el Noreste de la Provincia de Buenos Aires (Humedal del Paraná inferior). Tesis para optar al grado de Licenciado en Ciencias Antropológicas, Departamento de Ciencias Antropológicas, Fac. Filosofía y Letras, UBA, Buenos Aires.

----- 2010. "Bone Bipoints: Testing Functional Hypothesis". En Ancient and modern bone artefacts from America to Russia. Cultural, technological and 
functional signature, editado por A. Legrand-Pineau, I. Sidéra, N. Buc, E. David y V. Scheinsohn, pp: 217-226. Archeopress, Oxford.

2011. "Experimental series and use-wear in bone tools". Journal of Archaeological Science 38 (3): 546-557.

Buc, N. y D. Loponte. 2007. "Bone tool types and microwear patterns: Some examples from the Pampa region, South America”. En Bones as Tools: Current Methods and Interpretations in Worked Bone Studies, editado por C. St Pierre y R. Walker, pp: 143-157. BAR International Series, Oxford.

Buc, N. y R. Silvestre. 2006. "Funcionalidad y complementariedad de los conjuntos líticos y óseos en el humedal del nordeste de la Provincia de Buenos Aires: Anahí, un caso de estudio". Intersecciones en Antropología 7: 129-146.

Campana, D. 1989. Natufian and Protoneolithic Bone Tools. The Manufacture and Use of Bone Implements in the Zagros and the Levant. BAR International Series, Oxford.

Cartajena, I.; M. A. Benavente, L. Núñez y C. Thomas. 2009.” La utilización de los camélidos durante el Formativo Temprano: una comparación entre la cuenca del Loa medio y el Salar de Atacama”. En Zooarqueología y Tafonomía en el Confín del Mundo, editado por P. López, I. Cartajena, C. García y F. Mena, pp: 45-58. Universidad Internacional SEK, Santiago.

Cartajena, I.; P. López, B. Santandery D. Jackson. 2011. Análisiszooarqueológico y tafonómico del sitio MAU085. Informe de Avance Proyecto Arqueológico Mauro. Manuscrito en poder de los autores.

Cornejo, L. y D. Jackson. 2004. "Un Panorama del Patrón de Asentamientos en los Esteros Conchalí-Pupío (Los Vilos): Entre el Interior y la Costa”. Revista Werken 5: 83-87.

D'Errico, F. y P. Villa. 1997. "Holes and grooves. The contribution of microscopy and taphonomy to the problem of art origins". Journal of Human Evolution 33: $1-31$.

Eiroa García, J.; J. Bachiller Gil, L. Castro Pérez y J. Lomba Maurandi. 1999. Nociones de tecnología y tipología en Prehistoria. Ariel Historia, Barcelona.

García, Ch. 2006. "Los artefactos óseos de Marifilo 1. Una aproximación a la tecnología ósea entre cazadores recolectores de la selva valdiviana”. Revista Werken 8: 91-100.

González Morales, M. 1986. "La Riera bone and antler artifact assemblages". En La Riera cave. Stone age hunter-gatherer adaptations in Northern Spain, 
editado por L. O. Straus y G. A. CIark, pp: 209-218 y 385-419. Arizona State University, Arizona.

Jackson, D. 1990. "Retocadores extremo-laterales en contextos paleoindios". Anales del Instituto de la Patagonia 19: 121-124.

Jackson, D. y P. Peralta. 2011. Análisis lítico. Sitio MAU-085. Informe de Avance Proyecto Arqueológico Mauro. Manuscrito en poder de los autores.

Johnson, E. 1989. "Human modified bones from early southern Plains Sites". En Bone modifications, editado por R. Bonnichesen, pp: 431-471. University of Maine, Center for the Study of the Firsts Americans, Orono.

Julien, M.; A. Averbouh, D. Ramseyer, C. Bellier, D. Buisson, P. Cattelain, M. Patou-Mathis, M. y N. Provenzano. 2000. Préhistoire d'os. Recueil d'études sur l'industrie Osseuse Préhistorique offert à Henriette Camps-Fabrer. Université de Provence, Provence.

Latorre, E. 2011. Análisis de material metálico. Informe de Avance Proyecto Arqueológico Mauro. Manuscrito en poder de los autores.

Lucero, M. 2004. Evaluación del uso de Artefactos de Concha en el Poblamiento Inicial del Semiárido de Chile. Memoria para optar al título profesional de Arqueólogo, Facultad de Ciencias Sociales, Universidad de Chile, Santiago.

----- 2005. "Análisis de huellas de uso en instrumentos conquiológicos experimentales". Actas XVI Congreso Nacional de Arqueología Chilena, pp: 75-83. Sociedad Chilena de Arqueología. Tomé, Chile.

Lucero, M. y D. Jackson. 2005. "Shell tools in Early Holocene contexts: Studies of early settlements of the American Pacific Coast of Chile". Current Research in the Pleistocene 22: 2325.

Massone, M. 1988. "Artefactos óseos del yacimiento arqueológico Tres Arroyos (Tierra del Fuego)". Anales del Instituto de la Patagonia 20: 111-115.

Méndez, C. y A. Troncoso. 2004. "Editorial”. Revista Werken 5: 3-7.

Méndez, C. y D. Jackson. 2004. “Ocupaciones humanas del Holoceno Tardío en Los Vilos (IV Región, Chile): Origen y características conductuales de la población local de cazadores recolectores de litoral". Chungara 36 (2): 279-293.

----- 2008. "La ocupación prehispánica de Combarbalá (Norte Semiárido, Chile): una propuesta sintética". Chungará 40 (2): 5-17.

Méndez, C.; A. Troncoso, D. Jackson y D. Pavlovic. 2009. "Movilidad y uso del espacio entre cazadores-recolectores tardíos en espacios cordilleranos del Norte Semiárido de Chile”. Intersecciones en Antropología 10 (2): 311-326. 
Newcomer, M. 1974. "Study and Replication of Bone Tools from Ksar Akil (Lebanon)”. World Archaeology 6: 138-153.

Niemeyer, H.; Cervellino, M. y G. Castillo. 1997. Culturas Prehistóricas de Copiapó. Editorial Museo Regional de Atacama, Copiapó.

Olsen, S. 1979. "A study of Bone Artefacts from Grasshopper Pueblo, AZ P: 14: 1”. The Kiva 44 (4): 341-371.

Pavlovic, D. 2004. "Dejando atrás la tierra de nadie: Asentamientos, contextos y movilidad de las comunidades Alfareras Tempranas del Choapa". Werken 5: 39-46.

Peltier, A. y H. Plisson. 1989. "Microtraceologie fonctionnelle sur l'os. Quelques resultats experimentaux". Artefacts 3: 69-79.

Runnings, A.; C. Gustafson y D. Bentley. 1989. "Use-wear on bone tools: A technique for study under the scanning electron microscope". En Bone Modification, editado por R. Bonnischen y M. Sorg, pp: 259-266. University of Maine, Orono.

Santander, B. 2009. "Modelos secuenciales para tecnología ósea durante la transición Arcaico-Formativo en Atacama. El caso de la Quebrada Tulán”. En Zooarqueología y Tafonomía en el Confín del Mundo, editado por P. López, I. Cartajena, C. García y F. Mena, pp: 45-58. Universidad Internacional SEK, Santiago.

2010. La Industria Ósea y su Uso en Materiales Animales Blandos. Una Aproximación Traceológica a un Conjunto Arqueológico del Norte de Chile. Tesis para optar al grado de Máster Europeo en Cuaternario y Prehistoria, Universidade de Tras-os-Montes e Alto Douro, Instituto Politecnico de Tomar (Portugal), Universitat Rovira i Virgili (Espańa), Universidad degli studi di Ferrara (Italia), Museum national d' Histoire Naturelle (Francia).

----- 2011. Patrones de Huellas de Uso en Artefactos Óseos para el Periodo Formativo Temprano en la Puna de Atacama. El Sitio Tulan-54. Memoria para optar al Título profesional de Arqueólogo, Departamento de Antropología, Facultad de Ciencias Sociales, Universidad de Chile, Santiago.

Scheinsohn, V. 1993-1994."Hacia un modelo del aprovechamiento de materias primas óseas en la isla grande de Tierra del Fuego (Argentina)". Relaciones de la SociedadArgentina de Antropología XIX: 307-324.

1997. "Use wear patterns on bark removers". En Proceedings of the 1993 Bone Modification Conference, editado por L. Hannus, L. Rossum y R. Winhan, pp: 265-276. Archaeology Laboratory, Agusana College, Sioux Falls, South Dakota. 
Semenov, S. A. 1964. Prehistoric Technology. Cory, Adam and Machay, London.

Shipman, P. 1981. "Applications of scanning electron microscopy to taphonomic problems". En The Research Potential of Anthropological Museum Collections, editado por A. M. Cantwell, J. B. Griffin y N. Rotschild, pp: 357-385. Annals of the New York Academy of Sciences ,276.

Stone, E. 2011. Through the Eye of the Needle: Investigations of Ethnographic, Experimental, and Archaeological Bone Tool Use Wear from Perishable Technologies. Tesis para optar al grado académico de Doctor en Antropología, Universidad de Nuevo Mexico, USA.

Villa, P. y F. D'Errico. 2001. "Bone and ivory points in the Lower and Middle Paleolithic of Europe". Journal of Human Evolution 41: 69-112. 